\title{
Equivalent Geometric Imperfections for Local Buckling of Slender Box-section Columns
}

\author{
Mohammad Radwan ${ }^{1 *}$, Balázs Kövesdi ${ }^{1}$ \\ ${ }^{1}$ Department of Structural Engineering, Faculty of Civil Engineering, Budapest University of Technology and Economics, H-1111 \\ Budapest, Múegyetem rkp. 3., Hungary \\ * Corresponding author, e-mail: mohammad.radwan@emk.bme.hu
}

Received: 12 May 2021, Accepted: 18 August 2021, Published online: 10 September 2021

\begin{abstract}
Determining the plate or the local buckling resistance is highly important in designing steel buildings and bridges. The EN 1993-1-5 Annex $C$ provides a FEM-based design approach to calculate the buckling resistance based on numerical design calculations (geometrical and material nonlinear analysis - GMNIA). Within the GMNIA analysis-based stability design, the application of the imperfections has a special role. Thus, the applicability of the EN 1993-1-5 based buckling curve (Winter curve) has been questioned for pure compression, and previous investigations showed the buckling curve of EN 1993-1-5 Annex B is more appropriate for the design of slender box-section columns subjected to pure compression, the magnitude of the equivalent geometric imperfection to be applied in numerical models for local buckling is also questioned and investigated by the authors within the current paper. The aim of the current research program is to investigate the necessary equivalent geometric imperfections to be applied in FEM-based design calculations using GMNIA calculations. A numerical parametric study is executed to investigate the imperfection sensitivity of box-section columns having different local slenderness. The necessary imperfection magnitudes are determined to each analyzed geometry leading to the buckling resistance predicted by the standardized buckling curves. Based on the numerical parametric study, a proposal for the applicable equivalent geometric imperfection magnitude is developed, which conforms to the plate buckling curves of the EN 1993-1-5 and giving an improvement proposal to the local buckling imperfection magnitudes of the prEN 1993-1-14, which is currently under development.
\end{abstract}

\section{Keywords}

equivalent geometric imperfections, local buckling, FEM based design, GMNIA analysis

\section{Introduction}

The subject of the paper is the investigation of the local plate buckling resistance of slender box-section columns subjected to pure compression. The current EN 1993-1-5 [1] standard provides a design method using analytical design equations checking the buckling resistance to pure compression, which design method uses the Winter curve as a plate buckling curve. The applicability of this buckling curve has been questioned by several researchers in the past. Previous research results [2-4] showed that the required safety level of the Eurocode is not reached by using the formulae of the EN 1993-1-5 [1] for local buckling resistance of box-section columns. Therefore, Schillo et al. [3] proposed a new buckling curve or suggested using an increased partial safety factor for plate buckling resistance of plates subjected to pure compression and not supported by adjacent plates (for example, square box-section columns).
The proposed Schillo's new buckling curve is extremely close to the buckling curve used within the reduced stress method of the EN 1993-1-5 provided in Annex B (called as Annex B curve). Therefore, it has been proposed to use the Annex B curve for these special cases.

As the buckling curve has been changed for box-section columns subjected to pure compression, the equivalent geometric imperfections used in FEM based design of these structures also need revision because the previous imperfection magnitude ( $b / 200$ - where $b$ is the plate width) provided in the EN 1993-1-5 Annex $C$ had been calibrated to the Winter curve. The FEM-based design approaches are getting widely applied nowadays, which will be enforced by the publication of the new standard prEN 1993-1-14 "Design assisted by finite element analysis" [5]. The new code is currently under development which will 
provide design rules to finite element model-based design of steel structures. This new code will make the numerical calculation-based design widely standardized, and design rules will also be provided to designers on how to perform GMNIA analysis-based direct resistance checks. In the application of this design process, no buckling curves are applied, which had a test-based origin. Imperfections, especially equivalent geometric imperfections are having the aim to ensure the correct buckling resistance, which gives the need for the calibration of the imperfection magnitudes to the buckling curves, which are validated and proved by test results. Therefore, the current paper investigates the necessary imperfection magnitudes to be applied in the direct resistance check using GMNIA analysis made on shell element models to reach the local buckling resistance provided by the (i) Winter curve and the (ii) Annex B curve. Thus, both buckling curves are used in daily engineering practice. The necessary imperfection magnitudes are determined for both of them. Thus, the majority of the application of the imperfections in the design praxis are equivalent geometric imperfections covering the effect of the geometric imperfections and residual stresses. Therefore, the current investigations are limited to the investigation of this imperfection type.

\section{Literature review}

Nishino et al. [6] experimentally investigated welded stub columns in 1966. Specimens were made of ASTM A7 (A36, $f_{y}=250 \mathrm{~N} / \mathrm{mm}^{2}$ ), and ASTM A514 (quenched and tempered, $f_{y}=689 \mathrm{~N} / \mathrm{mm}^{2}$ ) steel material. The plate thickness of the box sections was $6.5 \mathrm{~mm}$. The width was varied from 170 to $290 \mathrm{~mm}$. The results of experiments indicated that considerable post-buckling strength might be expected for the elastic buckling of plates, although not for elastic-plastic buckling. Also, the effect of residual stresses on the buckling strength of the plate is investigated and found less pronounced for A514 steel than for A7 steel [6].

Dwight [7] experimentally investigated a set of 49 stub-column tests conducted at the engineering department in Cambridge in 1969. The study concluded that the equation for the effective width suggested by Winter is unsafe. It has been mentioned additionally that the American and British Standards had already changed in practice to lower reduction factors. In addition to the evaluation of the effective width, the study focused on the influence of residual stress. It was found that the width of the tension area should be independent of the plate width above a $b / t$-ratio of 25 [7].
In the experimental program of Chiew et al. [8], 20 steel box-section columns having square and rectangular cross-sections with various column slenderness and plate width-to-thickness ratios are tested to failure. Specimens were made of mild strength steel with a yield strength of $250 \mathrm{~N} / \mathrm{mm}^{2}$. The experimental program contained different types of sections. Therefore, several sections having relatively small global relative slenderness ratios against flexural buckling ( $\lambda$ less than 0.4 ) failed by local buckling. Bridge and O'Shea [9] executed local buckling tests on concrete-filled and unfilled steel stub columns. The columns were made of steel material with a yield strength of $f_{y}=282 \mathrm{~N} / \mathrm{mm}^{2}$. The tests were performed to investigate the behavior under an axial load of short, thin-walled, square steel tubes with or without internal restraint. Two test series were performed to study the effect of changing the buckling mode and the influence of the specimen length on the buckling shape. The research compared several international standards, including the American AISC-LRFD and the British standards. It was concluded that the British standards have a good estimation of the very slender plates while it is unconservative for thin plates. The authors suggested a further modification to the Winter formula that has a better agreement with the experiment results.

Shi et al. [10] performed thirteen welded stub column tests made of S460 steel grade in 2014. The length of the column was designed fitting to a nominal one local buckling half-wavelength to all test specimens. Therefore, these columns were sufficiently compact to avoid all overall buckling instabilities. Results show the local buckling stress $\sigma_{c r}$, the ultimate stress $\sigma_{u}$, and the stress ratio $\sigma_{c r} / \sigma_{u}$ decreases with the increase of the width-to-thickness ratios of plates $(b / t)$, indicating that local buckling occurs before yielding of the plate. Additionally, the post-buckling strength increased as the width-to-thickness ratio increased. It was also found that after applying suitable imperfections and residual stresses, FEM analyses could estimate accurately the ultimate strength of the specimens having different cross-sections. After the comparison of the test results and FE analysis estimated by the different codes, it was found that for box-section specimens, the current design methods are not always on the safe side.

Local buckling resistance according to EN1993-1-5 [1] is based on the effective width method derived by von Kármán et al. [11] and improved by Winter in 1968 [12] based on experimental results conducted on cold-formed sections subjected to bending moment. There are two 
reasons for the modification: (i) the cold-forming process results in advantages at the corners, which can increase the resistance, (ii) pure bending moment results in better support conditions than pure compression due to the supporting effect of adjacent plates. The modified design equation is given by Eq. (1), which is currently the basic design equation of the EN 1993-1-5 for local plate buckling within a slightly improved form in order to make the formula applicable to different loading situations.

$\rho=\frac{\mathrm{b}_{\text {eff }}}{b}=\frac{1}{\bar{\lambda}_{p}} \cdot\left(1-\frac{0.22}{\bar{\lambda}_{p}}\right), \bar{\lambda}_{p} \geq 0.673$,

where:

$b \quad$ is the plate width

$b_{e f f}$ is the effective width of the plate

$\bar{\lambda}_{p} \quad$ is the relative slenderness ratio.

Numerous researchers [2], [4], [13-16] compared the Winter curve to experimental or numerical results and concluded that the Winter curve provides approximately the mean value of the test result and provides larger resistance than the characteristic value of the plate buckling resistance. It means that this buckling curve does not fit the safety requirement of EN 1990 [17], and it needs revision.

Schillo et al. [2-4] executed a large experimental and numerical research program on the local buckling resistance of high-strength steel welded box sections and performed a detailed statistical evaluation to determine the characteristic and design resistance values and the corresponding buckling curves. The result of these investigations was a new lower bound curve proposed by Schillo et al. fitting the safety requirement of EN 1990 [17]. The new buckling curve is extremely close to the buckling curve of Annex B of EN 1993-1-5 given by Eqs. (2)-(4).

$$
\begin{aligned}
& \rho=\frac{1}{\phi_{p}+\sqrt{\phi_{p}^{2}-\bar{\lambda}_{\rho}}}, \\
& \varphi_{\rho}=\frac{1}{2}\left(1+\alpha_{\rho}\left(\bar{\lambda}_{\rho}-\bar{\lambda}_{\rho 0}\right)+\bar{\lambda}_{\rho}\right), \\
& \bar{\lambda}_{p}=\sqrt{\frac{\alpha_{u l t, k}}{\alpha_{c r}}},
\end{aligned}
$$

where: $\alpha_{u l t, k}$ is the minimum load amplifier for the design loads to reach the characteristic value of resistance of the most critical point of the plate and $\alpha_{c r}$ is the minimum load amplifier for the design loads to reach the elastic critical load of the plate according to EN 1993-1-5 [1].
Based on the detailed literature review, it can be concluded that many studies criticized the Winter curve and suggested a lower buckling curve to ensure enough safety. Within the current study, the buckling curve given in Annex B of the EN 1993-1-5 is considered as an appropriate alternative to the Winter curve as proved by Schillo et al. [2-4] and highlighted by Kövesdi [15]. However, if the buckling curve is changed, the equivalent imperfections should also be changed and harmonized with the buckling curve. Therefore, the aim of this study is to find the appropriate imperfections to be implemented in numerical models to obtain exactly the same ultimate resistance provided by the Winter curve or the Annex B curve.

\section{Numerical model development}

\subsection{Geometrical model and boundary conditions}

A full shell element model is developed to model the square box-section columns using four-node thin shell elements (Shell 181 element of the Ansys 19.0 [18] software). The geometry of the numerical model (with enlarged imperfections) is presented in Fig. 1. The length of the numerical model is always three times the width of the plate, having at least three buckling waves eliminating the disturbing effect of the support region on the buckling resistance. The two end cross-sections of the stub-column are supported, where rigid diaphragms are applied using rigid members connected to a node placed in the center of gravity of the cross-section. The rigid members link all the 6 DOFs between the coupled nodes. At one end of the segment, the center of gravity of the cross-section is restrained against translations (UX, UY, UZ) and rotation (ROTZ). At another end, only the UX, UY, ROTZ DOFs are restrained, to allow the deformation in the $Z$-direction, and compressive normal force (FZ) acting in the center of gravity of the cross-section is applied.

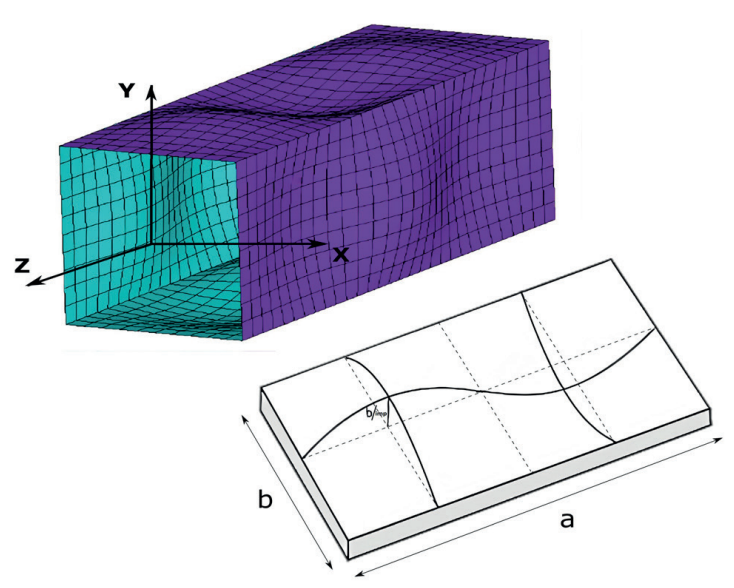

Fig. 1 Numerical model used for GMNIA simulation 
Imperfections included in the FE model should account for the effects of geometric deviations from the perfect shape, residual stresses, and boundary condition defects [6]. There are usually two methods to define imperfections:

a. geometric imperfections and additional residual stresses due to fabrication,

b. equivalent geometric imperfections by modification of the perfect shape of the structure; these imperfections are intended to cover the effect of both the geometrical imperfections and residual stresses and have larger magnitudes than solely geometric imperfections.

Version b (equivalent geometric imperfections) is applied in the current analysis; thus, the research aim was to determine the necessary magnitude for the equivalent geometric imperfections to achieve a specific buckling resistance. There are different methods to define equivalent geometric imperfections. The first possibility is the application of imperfection shapes based on predefined standardized functions or modification of the perfect shape by predefined displacements taken from the linear analysis. The second possibility is the application of imperfection shape based on linear bifurcation analysis (LBA) corresponding to the eigenmode (shape) associated with the expected failure mode. The third possibility is the application of the collapse-affine imperfection shapes. In the present study hand-defined imperfections using predefined shape is applied where the maximum amplitude is changed within the numerical parametric study. The shape of the local imperfection is a half-sine wave in both directions with a wavelength equal to the width of the panel, as presented in Fig. 1. No global imperfection is applied in the model to study the effect of local imperfections alone on the plate buckling resistance.

\subsection{Material model}

Different nonlinear material models are available in the literature, which will be standardized in the new prEN 19931-14 [5]. Details and background information on these material models are given in [19]. More advanced material models can also be found in the literature as presented by Budaházy and Dunai in [20]. In the current analysis, a quad-linear elastic-plastic material model is applied. The characteristic curve of the material model is shown in Fig. 2. The material model behaves linearly elastic up to the yield strength $\left(f_{y}\right)$ by obeying Hooke's law with Young's modulus $(E)$ equal to $210000 \mathrm{MPa}$. The yield plateau is modeled according to Eq. (5), and an isotropic hardening behavior is defined by Eqs. (6)-(9) are modeled until

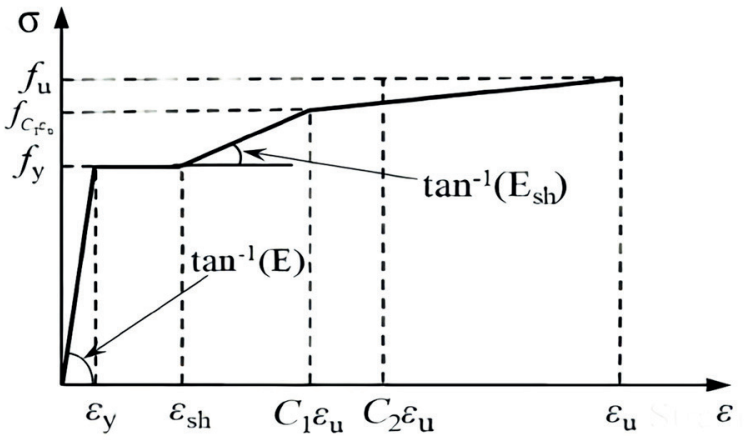

Fig. 2 Standardized material models for numerical calculations [6]

reaching the ultimate strength $\left(f_{u}\right)$. In the current analysis S235, S355, and S460 steel grades are applied. The relevant values of the material model are summarized in Table 1. This quad-linear material model is supposed to accurately capture the yield plateau and strain-hardening behavior of hot-rolled structural carbon steels, based upon and calibrated against a large dataset of tensile coupon tests [9].

$$
\begin{aligned}
& \varepsilon_{s h}=0.1 \frac{f_{y}}{f_{u}}-0.055, \text { but } 0.01 \leq \varepsilon_{s h} \leq 0.03, \\
& \varepsilon_{u}=0.6\left(1-\frac{f_{y}}{f_{u}}\right), \text { but } 0.06 \leq \varepsilon_{u}<A, \\
& C_{1}=\frac{\varepsilon_{s h}+0.25\left(\varepsilon_{u}-\varepsilon_{s h}\right)}{\varepsilon_{u}}, \\
& C_{2}=\frac{\varepsilon_{s h}+0.4\left(\varepsilon_{u}-\varepsilon_{s h}\right)}{\varepsilon_{u}}, \\
& E_{s h}=\frac{f_{u}-f_{y}}{C_{2} \varepsilon_{u}-\varepsilon_{s h}},
\end{aligned}
$$

where:

$\varepsilon_{y}=f_{y} / E \quad$ is the yield strain,

$\varepsilon_{s h} \quad$ is the strain hardening strain,

$E_{s h} \quad$ is the strain hardening modulus,

$A \quad$ is the elongation after fracture defined in the relevant material specification $(0.2$ is used in the current analysis),

$C_{1}$ and $C_{2}$ are material coefficients.

\subsection{Investigated parameter range}

The parameters varied in the numerical parametric study are the cross-section properties (width and thickness) and the steel grade. The cross-section width $(b$ and $h)$ is changed between $200-450 \mathrm{~mm}$. The thickness $(t)$ is varied between $2-10 \mathrm{~mm}$ within steps of $0.25 \mathrm{~mm}$. A total of $\sim 85$ different cross-section geometries are studied in the 
Table 1 Applied material model parameters

\begin{tabular}{lccc}
\hline & $\mathrm{S} 235$ & $\mathrm{~S} 355$ & $\mathrm{~S} 460$ \\
\hline$f_{y}$ & 235 & 355 & 460 \\
$f_{u}$ & 360 & 510 & 540 \\
$\varepsilon_{s h}$ & 0.010 & 0.015 & 0.030 \\
$\varepsilon_{u}$ & 0.208 & 0.182 & 0.089 \\
$C_{1}$ & 0.287 & 0.310 & 0.505 \\
$C_{2}$ & 0.430 & 0.448 & 0.604 \\
$E_{s h}$ & 1577.8 & 2310.0 & 3406.9 \\
$C_{1} * \varepsilon_{u}$ & 0.0598 & 0.0565 & 0.0449 \\
$f_{C_{1} e u}$ & 313.125 & 451.875 & 510 \\
\hline
\end{tabular}

current research program covering a relative slenderness ratio of 0.7 up to 2.8 . This is the typical slenderness range where local buckling occurs and which might occur in the daily design. Each cross-section is investigated, having three different steel grades presented in Section 3.2, leading to 250 different stub columns investigated. Within the numerical parametric study, geometries are selected having the same relative slenderness ratio but having different plate width or thickness values. This methodology allows to generalize the obtained conclusions and making them $b / t$ ratio independent.

\subsection{Analysis type and evaluation strategy}

Geometrical and material nonlinear analysis with imperfections (GMNIA) is applied to determine the characteristic buckling resistance of the analyzed stub columns. The full Newton-Raphson approach is used in the nonlinear analysis with $0.1 \%$ convergence tolerance of the residual force-based Euclidian norm. Within the nonlinear numerical calculations, equivalent geometric imperfections and nonlinear material models are applied. The result of the nonlinear analysis gives the behavior of the structure represented by a load-displacement path related to the chosen boundary conditions and analyzed load considering the effect of elastoplastic instability. Based on the maximum value of the computed load-displacement curve, the ultimate loads of the analyzed stub columns are determined.

Imperfection sensitivity analysis is executed for all investigated geometries, and the change in the buckling resistance with the imperfection magnitude is evaluated for all the $3 \times 85$ analyzed geometries. The appropriate equivalent geometric imperfection magnitudes providing a resistance equal to the resistance given by the (i) Winter curve and (ii) Annex B curve are determined for all the studied geometries individually. The required imperfection magnitudes are evaluated depending on the applied steel grade and local slenderness ratio. Finally, a conclusion is drawn regarding the required imperfection size to be applied in the design to ensure safe-sided and appropriate buckling resistance for slender square box-section columns.

\subsection{Validation of the numerical model}

The numerical model is verified through the comparison with several previous test results available in the international literature. To verify the model, the measured material properties of the analyzed specimens are applied. Only geometrical imperfections are used for the validation process having the currently standardized $b / 200$ imperfection magnitude. The samples were taken from two different research programs. The first set consists of five samples from Bridge's research program [9], and the remaining samples were taken from Schillo's experimental program [21]. The first set is $282 \mathrm{MPa}$ steel with plate slenderness ranging from 0.68 to 2.12 . The second set consists of different steel grades, including S500, S700, and S960, for a range of slenderness of 0.75 to 1.39 . The test program of Schillo has to be chosen because it is a quite recent research program having well-documented test results. The obtained failure mode is presented in Fig. 3, fitting the failure mode obtained in the tests. One example for the comparison of the measured and computed load-displacement curves is presented in Fig. 4, showing an extremely good match to the test results.

However, it should be mentioned that for some cases, the numerical model using $b / 200$ imperfection predicted smaller or larger buckling resistance than measured in the laboratory tests highlighting that the imperfection applied in the numerical model is not always perfect; it needs revision. Typically, in the smaller slenderness range, the numerical model underpredicted the test results, while in the large slenderness range overpredicted them.

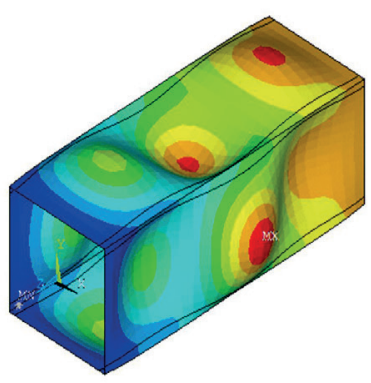

(a)

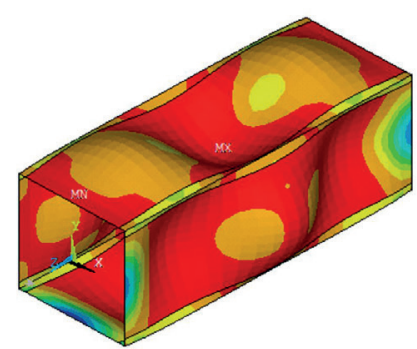

(b)
Fig. 3 Obtained failure mode local buckling; a) deformation, b) von Mises stresses 


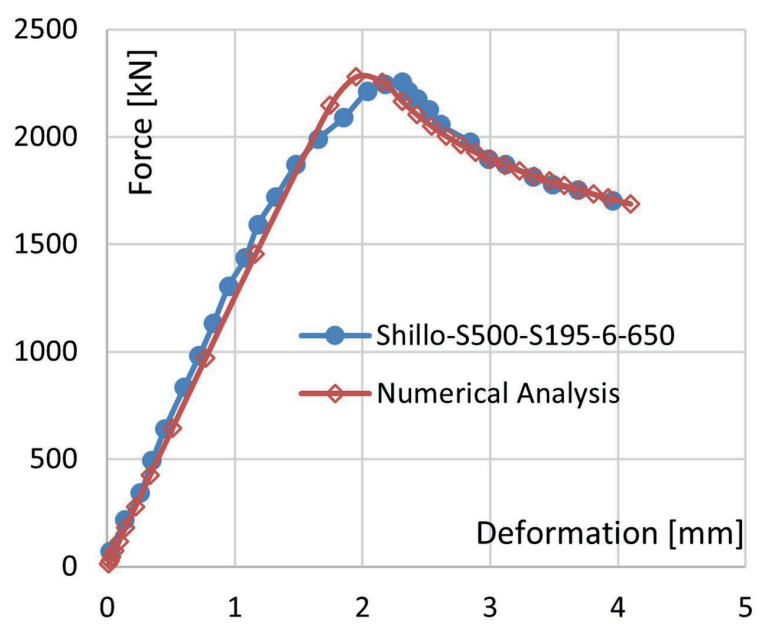

Fig. 4 Comparison of the measured and the computed load-deformation curves

\section{Results of the numerical parametric study}

In the numerical parametric study for each analyzed geometry, numerous numerical simulations (as imperfection sensitivity analysis) are executed having different imperfection magnitudes. To describe the applied imperfection size, the imperfection scaling factor $(f)$ is introduced as given in Eq. (10). Reduction factors for each calculation result are determined according to Eq. (11), which are plotted against its corresponding imperfection factor. One example for one specific geometry is presented in Fig. 5, where only the imperfection scaling factor is changed while keeping all the other parameters constant for the section under investigation.

Amplitude $=\frac{\text { width of the plate }(b)}{\text { imp. scaling factor }(f)}$,

$\rho=\frac{F_{\text {num. }}}{A_{c} \cdot f_{y}}$,

where:

$A_{c}$ is the area of the gross cross-section,

$f_{y}$ is the nominal value of the yield strength,

$F_{n u m}$ is the numerically calculated ultimate load.

On the horizontal axis, the imperfection scaling factor $(f)$ is presented, changing its value between 10 to 1200 . The results show that the reduction factor $(\rho)$ for local buckling is changing from 0.4 to 0.9 depending on the applied imperfection. This indicates that the imperfection factor has a significant effect on the ultimate resistance of the analyzed cross-section and can significantly alter the obtained results. It can be observed that decreasing the imperfection factor leads to a decrease in the ultimate resistance, decreasing the reduction factor. The analytically calculated

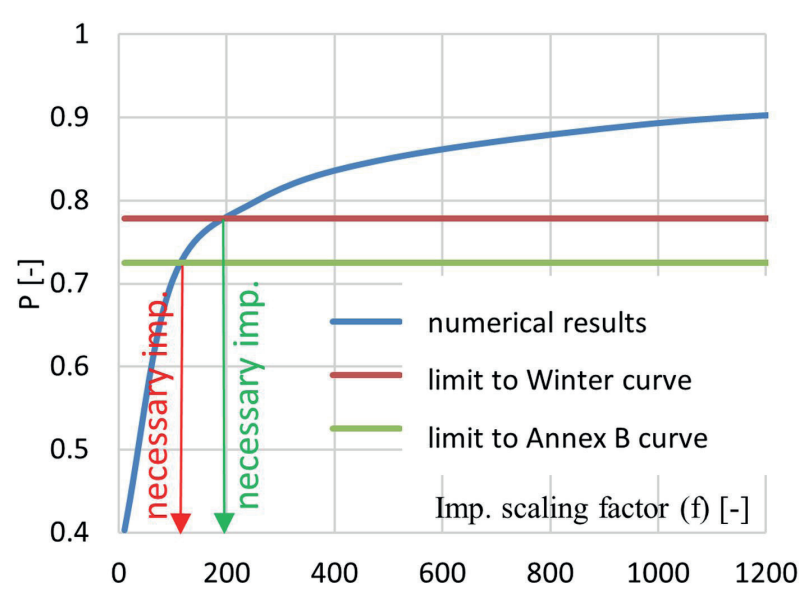

Fig. 5 Result of the imperfection sensitivity analysis for one specimen

values according to the Winter curve and Annex B curves are marked by horizontal lines on the graph. Taking the intersection point of both the lines representing the Winter curve or Annex B curve, the necessary imperfection scaling factors could be determined. The obtained scaling factors indicate the points where the Winter curve and Annex B curve results in exactly the same buckling resistance as predicted by the numerical model. For this one specific case, it can be seen that the necessary imperfection factor reaching the Winter curve is very close to the standard value $b / 200$. However, to reach the buckling resistance regarding the Annex B curve, a significantly larger imperfection (smaller imperfection scaling factor) should be applied. The same evaluation process has been made for all the $3 \times 85=255$ analyzed geometries, leading to more than 5000 GMNIA analyses using different slenderness ratios and equivalent geometric imperfections. For the S355 steel grade, the obtained results for all analyzed cross-sections are presented in Fig. 6. The horizontal axis shows the relative slenderness ratio of the plate, and the vertical axis

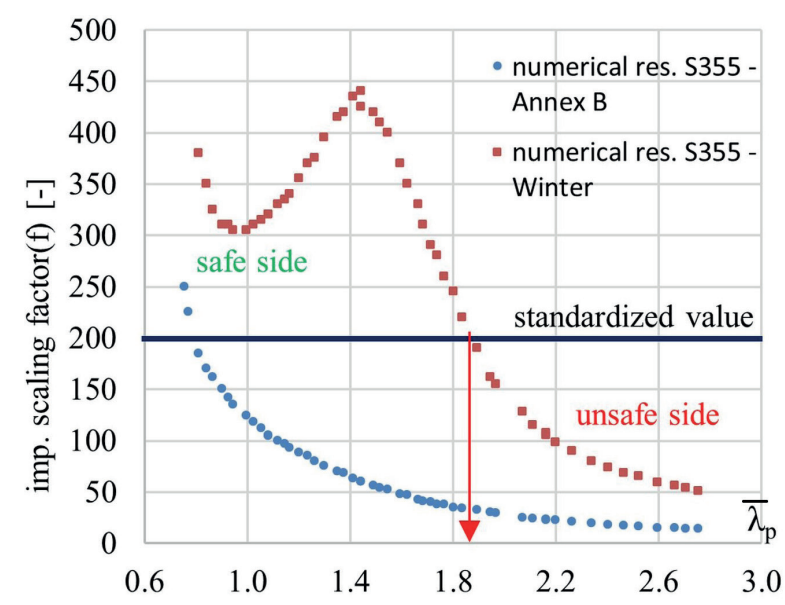

Fig. 6 Necessary imperfection scaling factor for S355 steel grade 
represent the obtained necessary imperfection scaling factor reaching the buckling resistance of the Winter curve (red squares in Fig. 6) and Annex B curve (blue points on Fig. 6), respectively.

Results show that the necessary imperfection strongly depends on the relative slenderness of the plate and cannot be given with one specific constant value resulting in always safe side resistance. Results prove the standardized imperfection $b / 200$ leads to smaller resistance than predicted by the Winter curve for the slenderness ratios $\bar{\lambda}_{p} \leq 1.85$. In the case of larger slenderness ratios, the numerical model results in larger resistances than predicted by the Winter curve. However, in the case of the Annex B curve, the required imperfection magnitude would be significantly larger within the entire slenderness range than the standardized value of $b / 200$.

The effect of the steel grade on the necessary imperfection factors is also investigated, and the numerical results for S235, S355, and S460 steel grades are also determined, evaluated, and plotted on the graph shown in Fig. 7. Results show that the yield strength has a significant effect on the necessary imperfection factor. Increasing the yield strength results in a slightly increased reduction factor (which is independent of the yield strength). Therefore, larger imperfections are needed to be applied, resulting in the same buckling resistance as predicted by the Winter curve or the Annex B curve. In Fig. 7, the order of the notations follows the order of the obtained curves. Results related to the S235 steel grade lead to the larger scaling factor, and results regarding the steel grade of S460 leads to the smaller one.

\section{Design proposal for applicable imperfection size}

It can be observed in the results presented in Section 4 that there is a large difference in the necessary imperfection scaling factors depending on the target buckling curve and the applied steel grade. Therefore, design recommendations are determined separately for the imperfection factor reaching the Winter curve and the Annex B curve. The parameters of the design equations are determined depending on the plate relative slenderness ratio $\left(\bar{\lambda}_{p}\right)$ and the yield strength of the material $\left(f_{y}\right)$. Lower bound curves to the numerical results are presented in Fig. 8 separately to all the three analyzed steel grades.

The related proposed design equations are given by Eqs (12)-(14), where the yield strength should be given in $[\mathrm{MPa}]$ in the equations. The recommended design curves to the Winter curve contains a constant value for the relative slenderness range of $\bar{\lambda}_{p} \leq 1.70$ then for larger

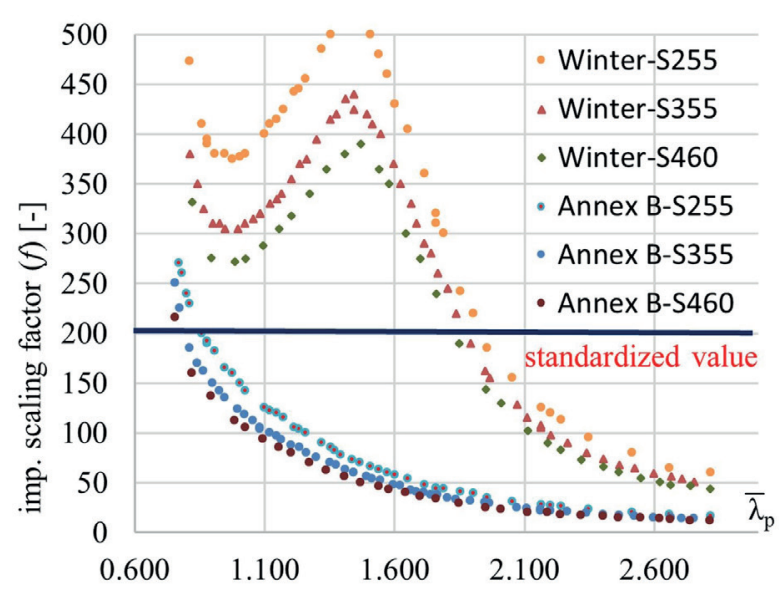

Fig. 7 Relationship between the plate slenderness $\bar{\lambda}_{p}$ and the imperfection scaling factor $(f)$ for different steel grades

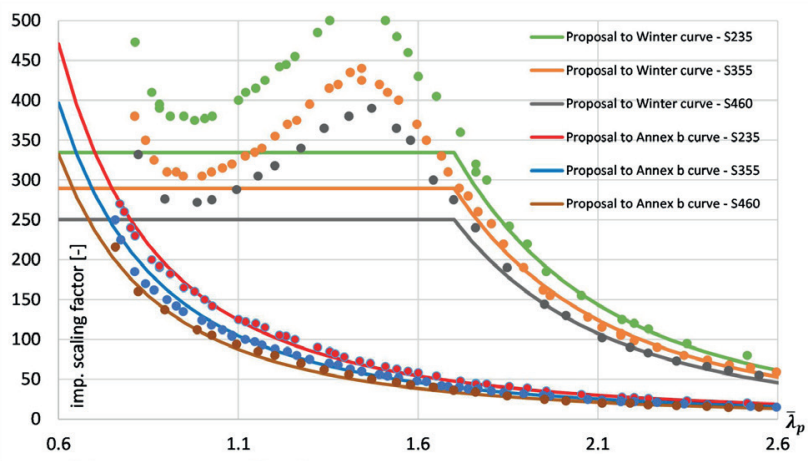

Fig. 8 Design proposals for the imperfection scaling factor $(f)$

slenderness value, smaller scaling factors should be applied depending on the value of the $\bar{\lambda}_{p}$ and $f_{y}$. In the case of the Annex B curve, the necessary imperfection scaling factor can be given by one expression also depending on the $\bar{\lambda}_{p}$ and $f_{y}$ values.

Design proposal to the Winter curve:

$f=\frac{3525-3.12 \cdot f_{y}}{8.35}$ if $\bar{\lambda}_{p} \leq 1.7$,

$f=\frac{1}{\bar{\lambda}_{p}^{4}} \cdot\left(3525-3.12 \cdot f_{y}\right)$ if $\bar{\lambda}_{p}>1.7$

Design proposal to the Annex B curve:

$f=\frac{1}{\bar{\lambda}_{p}^{2.2}} \cdot\left(200-0.2 \cdot f_{y}\right)$.

To check the accuracy and precision of the proposed equations, statistical evaluation is executed on the numerical database. The imperfection magnitudes are calculated by Eqs. (12)-(14) are applied in the numerical model, and the computed buckling resistances are compared to the Winter curve and the Annex B curve, respectively. The ratio of the numerical and analytical buckling resistance 
is determined for all analyzed cross-sections and steel grades, and the statistical evaluation is performed on this newly generated database.

Tables 2-3 presents the results, including the mean value, standard deviation, minimum and maximum values for both buckling curves. It can be observed that the proposed imperfection magnitudes give good agreement to the buckling curves, which are theoretically well established and proved for design purposes.

Results also prove that the necessary imperfections can be significantly larger than the previously given and usually used value $(b / 200)$, especially for cross-sections having a large relative slenderness ratio. The accuracy of the obtained results is double-checked by the authors, and based on the detailed investigation, the following conclusions are drawn:

- To reach the buckling resistance according to the Winter-type curve, larger imperfections than the usually used value $(b / 200)$ could also be necessary for cross-sections having a relatively large slenderness ratio. It is proved that the Winter-type curve currently used in the buckling resistance calculation of plated structures is not conservative and can overestimate the buckling resistance in the case of square box-sections. It means, to reach lower, safe-sided resistance, larger imperfections (smaller imp. scaling factors) are necessary to be applied.

- Based on the executed imperfection sensitivity analysis, it turned out, for cross-sections having a large relative slenderness ratio, the imperfection sensitivity is small. Indeed, the elastic buckling is dominant,

Table 2 Results of the statistical analysis for Annex B curve

\begin{tabular}{lc}
\hline Statistical measure/curve & Annex B (S235; S355; S460) \\
\hline Number of tests & 131 \\
Mean & 1.002 \\
Standard deviation & 0.012 \\
Skewness & 0.189 \\
Minimum value & 0.942 \\
Maximum value & 1.050 \\
\hline
\end{tabular}

Table 3 Results of the statistical analysis for Winter curve

\begin{tabular}{lc}
\hline Statistical measure/curve & Annex B (S235; S355; S460) \\
\hline Number of tests & 131 \\
Mean & 1.028 \\
Standard deviation & 0.018 \\
Skewness & 0.189 \\
Minimum value & 0.977 \\
Maximum value & 1.112 \\
\hline
\end{tabular}

the post-buckling reserve can be utilized. Therefore, to decrease the obtained buckling resistance within the numerical model, larger imperfections are to be applied, leading to the obtained small imperfection scaling factors.

As a further research task, the accuracy of the Annex B curve should be checked and validated by test results for a larger relative slenderness ratio than 1.8-2.0. Based on the improved buckling curve for larger slenderness ratios, the necessary imperfection magnitudes can be proof-checked and superseded.

\section{Summary and conclusions}

In the current paper, the equivalent geometric imperfections to be used in GMNIA analysis to determine the plate buckling resistance are investigated. The current standard proposal of the EN 1993-1-5 Annex C, and the future code provision of the prEN1993-1-14 is currently revised, and a new design proposal is developed. Thus, the applicability of the Winter curve for the buckling resistance prediction of square box-section columns has been questioned by several researchers in the past, and the buckling curve of the EN 1993-1-5 Annex B has been found appropriate based on test results and detailed statistical evaluation; the Annex B curve is considered in the current study as an appropriate buckling curve providing the characteristic value of the buckling resistance with large accuracy. Therefore, the necessary magnitudes of the equivalent geometric imperfections are determined for a wide slenderness range for three steel grades (S235, S355, and S460), providing the buckling resistance fitting to the Winter curve and the Annex B curve. The presented imperfection magnitudes are valid for the buckling resistance calculation of square box-section columns. The new design proposals can be used in the FEM-based design of steel structures to determine the plate buckling resistance. Depending on the buckling curve to be applied, two proposals are provided. Both of them are given in function of the relative slenderness ratio and the yield strength of the applied steel grade.

\section{Acknowledgment}

The presented research program has been financially supported by the Grant MTA-BME Lendület LP2021-06/2021 "Theory of new generation steel bridges" program of the Hungarian Academy of Sciences and Stipendium Hungaricum Scholarship and by the National Research, Development and Innovation Office (grant K 119440, TKP2020 NC, Grant No. BME-NCS). Both grants are gratefully acknowledged. 


\section{References}

[1] CEN "EN1993-1-5:2005 Eurocode 3 - Design of steel structures - Part1-5: Plated Structural elements", European Committee for Standardization, Brussels, Belgium, 2006.

[2] Schillo, N., Feldmann, M. "Local buckling behaviour of welded box sections made of high-strength steel - Comparing experiments with EC3 and general method", Steel Construction - Design and Research, 8(3), pp. 179-186, 2015.

https://doi.org/10.1002/stco.201510028

[3] Schillo, N., Taras, A., Feldmann M. "Assessment of safety factor for local buckling", presented at CEN/TC250/SC3/WG5 Meeting, Stuttgart, Germany, Feb. 26, 2016.

[4] Schillo, N., Taras, A. Feldmann, M. "Assessing the reliability of local buckling of plates for mild and high strength steels", Journal of Constructional Steel Research, 142, pp. 86-98, 2018. https://doi.org/10.1016/j.jcsr.2017.12.001

[5] CEN "prEN 1993-1-14:2020 Eurocode 3: Design of steel structures, Part 1-14: Design assisted by Finite element analysis", European Committee for Standardization, Brussels, Belgium, 2006.

[6] Nishino, F., Ueda, Y., Tall, L. "Experimental Investigation of the Buckling of Plates with Residual Stresses", In: Test Methods for Compression Members, ASTM International, West Conshohocken, PA, USA, 1967, pp. 12-30.

https://doi.org/10.1520/STP43785S

[7] Dwight, J. B., Moxham, K. E. "Welded Steel Plates in Compression", The Institution of Structural Engineers, 47(2), pp. 49-66, 1969. [online] Available at: https://www.istructe.org/journal/volumes/ volume-47-(published-in-1969)/issue-2/welded-steel-plates-incompression/

[8] Chiew, S.-P., Lee, S.-L., Shanmugam, N. E. "Experimental Study of Thin-Walled Steel Box Columns", Journal of Structural Engineering, 113(10), pp. 2208-2220, 1987.

https://doi.org/10.1061/(ASCE)0733-9445(1987)113:10(2208)

[9] Bridge, R. Q., O'Shea, M. D. "Behaviour of thin-walled steel box sections with or without internal restraint", Journal of Constructional Steel Research, 47, pp. 73-91, 1998. https://doi.org/10.1016/S0143-974X(98)80103-X

[10] Shi, G., Zhou, W., Bai, Y., Lin, C. "Local buckling of 460MPa high strength steel welded section stub columns under axial compression", Journal of Constructional Steel Research, 100, pp. 60-70, 2014. https://doi.org/10.1016/j.jcsr.2014.04.027
[11] von Kármán, T., Sechler, E. E., Donnel, L. H. "The Strength of Thin Plates in Compression", In: Transactions, ASME, New York, NY, USA, 1932, pp. 53-57. [pdf] Available at: https://www.ce.jhu.edu/ cfs/cfslibrary/von\%20karman\%20eff\%20width\%20paper.pdf

[12] Winter, G. "Strength of Thin Steel Plates Compression Fanges", Transactions of the American Society of Civil Engineers, 112(1), pp. 527-554, 1947.

https://doi.org/10.1061/TACEAT.0006092

[13] Bridge, R. Q., O'Shea, M. D. "Behaviour of thin-walled steel box sections with or without internal restraint", Journal of Constructional Steel Research, 47(1-2), pp. 73-91, 1998. https://doi.org/10.1016/S0143-974X(98)80103-X

[14] Pircher, M., O'Shea, M. D., Bridge, R. Q. "The influence of the fabrication process on the buckling of thin-walled steel box sections", Thin-Walled Structures, 40(2), pp. 109-123, 2002. https://doi.org/10.1016/S0263-8231(01)00055-6

[15] Kövesdi, B. "Plate-like Buckling Resistance of Longitudinally Stiffened Plates Subjected to Pure Compression", Periodica Polytechnica Civil Engineering, 63(2), pp. 621-630, 2019. https://doi.org/10.3311/PPci.13553

[16] Sinur, F. "Behaviour of longitudinally stiffened girders under combination of high bending and shear loading", $\mathrm{PhD}$ thesis, University of Ljubljana, 2011.

[17] CEN "EN 1990 Eurocode - Basis of structural design", European Committee for Standardization, Brussels, Belgium, 2005.

[18] Ansys Inc. "ANSYS® (17.2)", [computer program] Available at: https://www.ansys.com/ [Accessed: 5 December 2020]

[19] Gardner, L., Yun, X., Fieber, A., Macorini, L. "Steel Design by Advanced Analysis: Material Modeling and Strain Limits", Engineering, 5(2), pp. 243-249, 2019. https://doi.org/10.1016/j.eng.2018.11.026

[20] Budaházy, V., Dunai, L. "Parameter-refreshed Chaboche model for mild steel cyclic plasticity behaviour", Periodica Polytechnica Civil Engineering, 57(2), pp. 139-155, 2013. https://doi.org/10.3311/PPci.7170

[21] Schillo, N. "Local and global buckling of box columns made of high strength steel", PhD thesis, RWTH Aachen University, 2017. [pdf] Available at: https://publications.rwth-aachen.de/record/697419/ files/697419.pdf 